\title{
PEMBUATAN KAMPAS REM MENGGUNAKAN VARIASI BUTIRAN MESH ALUMUNIUM SILICON (Al-Si) 50, 60, 100 DENGAN SERBUK KAYU JATI TERHADAP NILAI TINGKAT KEKERASAN, KEAUSAN DAN KOEFISIEN GESEK
}

\author{
Pramuko Ilmu Purboputro \\ Fakultas Teknik, Program Studi Teknik Mesin \\ Universitas Muhammadiyah Surakarta \\ Email: pip272@ums.ac.id \\ Mohammad Nabila \\ Fakultas Teknik, Program Studi Teknik Mesin \\ Universitas Muhammadiyah Surakarta
}

\begin{abstract}
ABSTRAK
Pada penelitian ini, peneliti ingin membuat dan meneliti sampel kampas rem sepeda motor dengan menggunakan bahan komposit yang ramah lingkungan dengan menggunakan bahan alami yaitu serbuk kayu jati dengan variasi butiran Mesh untuk mengetahui nilai kekerasan, keausan dan koefisien gesek kampas rem tersebut. Bahan yang digunakan dalam penelitian ini adalah Serbuk Kayu Jati, Kalsium Karbonat, Barium Sulfat, Resin Phenolic, Karbon Kayu Sonokeling, dan Alumunium Silicon (Al-Si) dengan variasi Mesh 50,60 dan 100. Kemudian diuji kekerasan menggunakan alat Durometer dengan standar ASTM D2240, dan diuji gesek dengan beban $16 \mathrm{~kg}$ selama 3 jam dengan uji kering, uji basah, uji air garam, uji minyak rem, dan uji oli, serta dihitung keausan dan koefisien geseknya. Dari hasil uji kekerasan nilai tertinggi terdapat pada variasi Mesh Alumunium Silicon (AlSi) Mesh 100 dengan nilai kekerasan 81,60 HD. Hasil pengujian gesek pada semua kondisi nilai keausan terendah terdapat pada variasi Alumunium Silicon (Al-Si) mesh 100 yaitu pengujian kering $253,13 \mathrm{~mm}^{3} / \mathrm{jam}$, air $182,29 \mathrm{~mm}^{3} / \mathrm{jam}$, oli $352,08 \mathrm{~mm}^{3} / \mathrm{jam}$, air garam $243,75 \mathrm{~mm}^{3} / \mathrm{jam}$, minyak rem $341,67 \mathrm{~mm}^{3} / \mathrm{jam}$, Dan hasil nilai koefisien gesek tertinggi bervariasi nilai koefisien gesek tertinggi saat kondisi kering yaitu pada variasi Mesh 100 dan merk pasaran 0,651, saat kondisi air dan air garam yang tertinggi pada variasi Mesh 50, 0,658 dan 0,614 sedangkan saat kondisi oli dan minyak rem yang tertinggi pada variasi Mesh 60, 0,621 dan 0,613.
\end{abstract}

Kata kunci: komposit, serbuk kayu jati, alumunium silicon, variasi butiran mesh.

\begin{abstract}
In this study, researchers wanted to make and examine samples of motorcycle brake linings using environmentally friendly composite materials using natural materials namely teak wood powder with a variety of mesh grains to determine the value of hardness, wear and friction coefficient of brake lining. The materials used in this study is Teak Wood Powder, Calcium Carbonate, Barium Sulfate, Phenolic Resin, Sonokeling Wood Carbon, And Aluminum Silicon (Al-Si) with Mesh variations of 50.60 and 100. Then the hardness was tested using a Durometer with ASTM D2240 standard, and tested for friction with a load of $16 \mathrm{~kg}$ for 3 hours with dry test, wet test, salt water test, brake oil test, and oil test, and calculated the wear and coefficient of friction. From the results of the hardness test the highest value is found in the variation of Aluminum Silicon (Al-Si) Mesh 100 with a hardness value of $81.60 \mathrm{HD}$. The results of friction testing on all conditions of the lowest wear values are in the variation of Aluminum Silicon (Al-Si) Mesh 100 which is dry testing $253.13 \mathrm{~mm}^{3} / \mathrm{hour}$, water 182.29 $\mathrm{mm}^{3} /$ hour, oil $352.08 \mathrm{~mm}^{3} / \mathrm{hour}$, brine $243,75 \mathrm{~mm}^{3} /$ hour, brake fluid $341.67 \mathrm{~mm}^{3} / \mathrm{hour}$, and the results of the highest friction coefficient varied the highest coefficient of friction during dry conditions, namely in the Mesh 100 and market brands of 0.651, when the water and brine conditions were highest in the 50 Mesh variation 0.658 and 0.614 while when the oil and brake fluid conditions are highest in Mesh variations 60, 0.621 and 0.613 .
\end{abstract}

Keyword: composite, teak wood powder, aluminum silicon, variation of mesh granules.

\section{PENDAhuluan}

Semakin meningkatnya perkembangan jaman, kebutuhan manusia ikut berkembang. Karena perkembangan manusia bertambah maju di bidang teknologi juga ikut berkembang untuk menyesuaikan kemajuan, maka dari itu perlu dilakukan manajemen dalam proses produksi dengan harapan segala kebutuhan manusia dapat terpenuhi.

Jika diperhatikan kebutuhan manusia tidak bisa lepas dari kendaraan bermotor. Maka dari itu kita juga harus dapat memenuhi kebutuhan untuk memperbaiki atau memenuhi suatu komponen kendaraan bermotor, salah satu komponen kendaraan yang penting dan sering diganti yaitu kampas rem yang ada pada sistem pengereman kendaraan bermotor.

Sistem rem berfungsi untuk memperlambat atau menghentikan gerakan dari roda sehingga gerak roda menjadi lambat. Energi kinetik yang hilang dari benda yang bergerak ini diubah menjadi panas karena adanya 
gesekan. Jika rem tidak berfungsi dengan baik, maka dipastikan akan berakhir dengan kecelakaan. Faktor keamanan dari pengendara adalah hal yang sangat penting. Sehingga setiap produsen kendaraan bermotor merancang sistem dan menggunakan komponen rem (kampas rem) yang sesuai dengan kemampuan kendaraan. Menurut bentuknya ada dua jenis model kampas yaitu kampas rem cakram dan tromol. Pada kampas rem cakram, luas kampas tergolong lebih kecil dan kampas menempel pada pad yang berbahan keras.

Kampas rem asbestos adalah kampas rem yang berbahan asbestos 40-60\% resin $12-15 \%$, sisanya karet ban bekas, tembaga dan biasanya untuk meningkatkan koefisien gesek persentase metal di tambah. Kampas rem jenis asbestos banyak beredar dengan harga yang murah dan menjamin keawetan kampas rem,akan tetapi hasil dari serbuk gesekan yang berupa partikel kecil sangat berbahaya bagi kesehatan manusia.

Asbes dapat mempengaruhi kesehatan bila seratnya terhirup. Sekali terhirup serat tersebut akan bertahan di dalam jaringan paru. Terhirup serat asbes merupakan risiko kesehatan yang serius yang dapat menyebabkan penyakit mesotelioma, kanker paru dan asbestosis. Asbestos adalah gangguan pernafasan yang disebabkan oleh terhirupnya serat asbes. Akumulasi yang berkelanjutan dari serat tersebut dapat menyebabkan pembentukan jaringan parut pada paru dan sesak nafas.

Karena untuk memenuhi kebutuhan dan untuk meningkatkan kualitas kampas rem agar aman untuk kesehatan manusia, maka diadakan pemilihan bahan untuk mengganti penggunaan bahan berbahaya seperti asbestos dan diganti dengan menggunakan bahan yang lebih alami.

Pemilihan bahan tersebut dipersempit sesuai dengan kegunaannya, seperti dengan tujuan meningkatkan kualitas kampas rem yang ramah lingkungan serta dengan harga yang lebih terjangkau, maka penelitian ini menggunakan bahan alami seperti serbuk kayu jati yang didapat dari potongan pohon jati sebagai campurannya. Kemudian ada beberapa pemilihan bahan antara lain Karbon Kayu Sonokeling, Phenolic Resin, dan Alumunium Silicon dengan variasi butiran Mesh 50, 60, dan 100.

Serbuk Kayu Jati, merupakan salah satu bentuk limbah industri penggergajian kayu jati dan belum banyak dimanfaatkan. Hasil penelitian pada beberapa industri penggergajian kayu jati di Sulawesi Sdelatan menunjukkan bahwa limbah yang dihasilkan rata-rata 52,56\% dari bahan baku pohon jati yang digunakan, termasuk di antaranya bentuk serbuk. Serbuk gergaji mengandung komponen utama Selulosa, lignin dan zat ekstraktif kayu. Serbuk kayu merupakan bahan berpori sehingga air mudah terserap dan mengisi pori-pori tersebut. Sifat serbuk gergaji yang higroskopik atau mudah menyerap air. Serbuk kayu Jati sendiri mengandung sifat Selulosa.

Phenolic Resin merupakan resin sintetik yang terbuat dengan mereaksikan Phenol dengan Formaldehide, wujudnya keras, kuat, dan dapat dicetak pada berbagai kondisi. Bahan ini mempunyai kondisi tahan panas dan air yang baik, juga dapat diberi macam-macam warna, seiring digunakan sebagai bahan pelapis, laminating, pengikat batu gerinda, pengikat logam, atau gelas, sehingga Phenolic Resin berfungsi sebagai penyusun matrik yang bagus karena bersifat Thermosetting sehingga bila bahan itu aus maka akan menjadi debu dan terurai.

Karena itu pada penelitian ini penulis dituntut untuk membuat dan mengembangkan kampas rem yang berbahan ramah lingkungan dan memiliki kekerasan, keausan, dan koefisien gesek yang baik agar sesuai dengan kebutuhan yang diharapkan.

\section{METODE PENELITIAN}

Penelitian ini menggunakan rancangan untuk mendapatkan data yang aktual dengan langkah-langkah yang telah disusun secara sistematis. Metodologi penelitian ini merupakan salah satu cara untuk mempermudah membaca, menganalisa penelitian, dan memberikan gambaran umum proses penelitian dari awal sampai akhir pengujian sehingga mendapatkan data yang diperlukan.

Lokasi penelitian dilaksanakan di dua tempat yaitu: 1). Untuk pembuatan kampas dan pengujian Gesek dilakukan di Windan Rt 03/ Rw III Gumpang Sukoharjo pada tanggal 24 Januari sampai 6 April 2019. 2). Untuk pengujian kekerasan durometer dilakukan di Windan Rt 03/ Rw III Gumpang Sukoharjo pada tanggal 28 Februari 2019. 3). Untuk pengujian foto macro dilakukan di Laboratorium Teknik Mesin Universitas Muhammadiyah Surakarta pada tanggal 12 Maret 2019.

Penelitian dilakukan dengan cara mencari bahan-bahan pembuatan kampas rem dan mencari referensi yang ada untuk menunjang validasi data. Setelah bahan-bahan didapatkan kemudian diproses sesuai dengan bentuk yang diinginkan. Untuk proses pencampuran bahan-bahan material, dicampur secara manual agar hasil dari pencampuran material dapat bercampur secara merata. Setelah bahan-bahan tercampur semua, bahan dimasukkan kedalam Dies atau cetakan. Langkah selanjutnya yaitu pengepressan dengan tekanan 5,5 ton sampai suhu $100^{\circ} \mathrm{C}$ bila sudah tercapai di pres lagi 17 ton selama 8 menit Setelah spesimen dicetak kemudian dilakuan proses oven dengan suhu $160{ }^{\circ} \mathrm{C}$ selama 30 menit.

Kampas rem serbuk kayu jati variasi Mesh 50,60, dan 100, masing-masing mesh dicetak sebanyak 5 pasang spesimen dan ditambah 5 pasang spesimen kampas rem Pasaran, dengan jumlah total spesimen uji adalah 20 pasang spesimen. Spesimen dari masing-masing jenis kampas rem serbuk kayu jati variasi serbuk Mesh 50,60, dan 100 dengan spesimen lain yaitu kampas rem pasaran digunakan untuk pengujian foto macro, lalu digunakan untuk pengujian kekerasan menggunakan Durometer. Setelah semua spesimen 
selesai di uji kekerasan maka selanjutnya digunakan untuk pengujian gesek. Pengujian dilakukan pada kondisi kering, basah (air), air garam, minyak rem, dan oli yang mengacu pada standar SNI 09-2663-1992.

Pada saat pengujian gesek dilakukan, maka piringan cakram berputar dan kampas rem mulai diuji. Pada saat piringan cakram berputar maka akan terjadi gesekan dan menimbulkan panas. untuk mengetahui panas yang terjadi pada piringan cakram dan panas kampas rem maka dilakukan pembacaan suhu dengan menggunakan Infrared Thermometer yaitu dengan menyorotkan laser kepiringan dan kampas maka akan diketahui berapa suhu yang diukur.

Untuk mengetahui berapa putaran piringan cakram, maka digunakan alat pengukur putaran atau Tachometer. Tachometer ini berjenis Non-contact yaitu menggunakkan sinar laser yang ditembakkan ke benda yang akan diukur yang sebelumnya telah diberi stiker. Stiker ini berfungsi sebagai sensor pada Tachometer jenis ini.

Untuk mengetahui voltase dan ampere yang di derita oleh mesin gesek, maka digunakkan clamp meter. Untuk pembacaan ampere, clamp meter dijepitkan ke salah satu kabel. Sedangkan untuk pembacaan voltasenya alat ini menggunakaan kabel kontak yang dikontakkan pada sumber dari motor atau dinamo. Untuk mengetahui ketinggian spesimen sebelum pengujian gesek dan setelah pengujian gesek, maka digunakan Vernier Caliper (Jangka Sorong).

Analisis data setelah pembuatan kampas rem serbuk kayu jati variasi serbuk Mesh 50,60, dan 100. Setelah itu dilakukan uji gesek untuk tiap-tiap spesimen yaitu dengan cara mengukur ketinggian awal sebelum dan sesudah pengujian dilakukan setelah itu di rata-rata dengan Vernier Caliper / Jangka sorong, mengukur suhu kampas sebelum dan sesudah pengujian dengan Non- contact Infrared Thermometer kapasitas $-50^{\circ} \mathrm{C}$ sampai $280^{\circ} \mathrm{C}$, mengukur suhu cakram sebelum dan sesudah pengujian menggunakan Non-contact Infrared Thermometer, mengukur Voltase, Ampere menggunakan Clamp Meter dan putaran dari motor dengan menggunakan Digital Tachometer.

Untuk pengujian kekerasan Durometer, dilakukan dengan menekan pada tiga titik berbeda pada tiap spesimen, kemudian dicari rata-rata nilai kekerasannya.

\section{HASIL DAN PEMBAHASAN}

\subsection{Hasil pengujian foto macro kampas rem sebelum digesek}

3.1.1. Foto Macro Kampas Rem Mesh 50 Sebelum Digesek

Kampas rem variasi Mesh 50 mempunyai ikatan partikel yang cukup baik, tetapi untuk permukaan kampas kurang rata dan dapat diketahui ukuran alumunium silicon senilai 50 Mesh atau mendekati $300 \mu \mathrm{m}$. Hal ini dapat dilihat pada gambar 1 berikut:

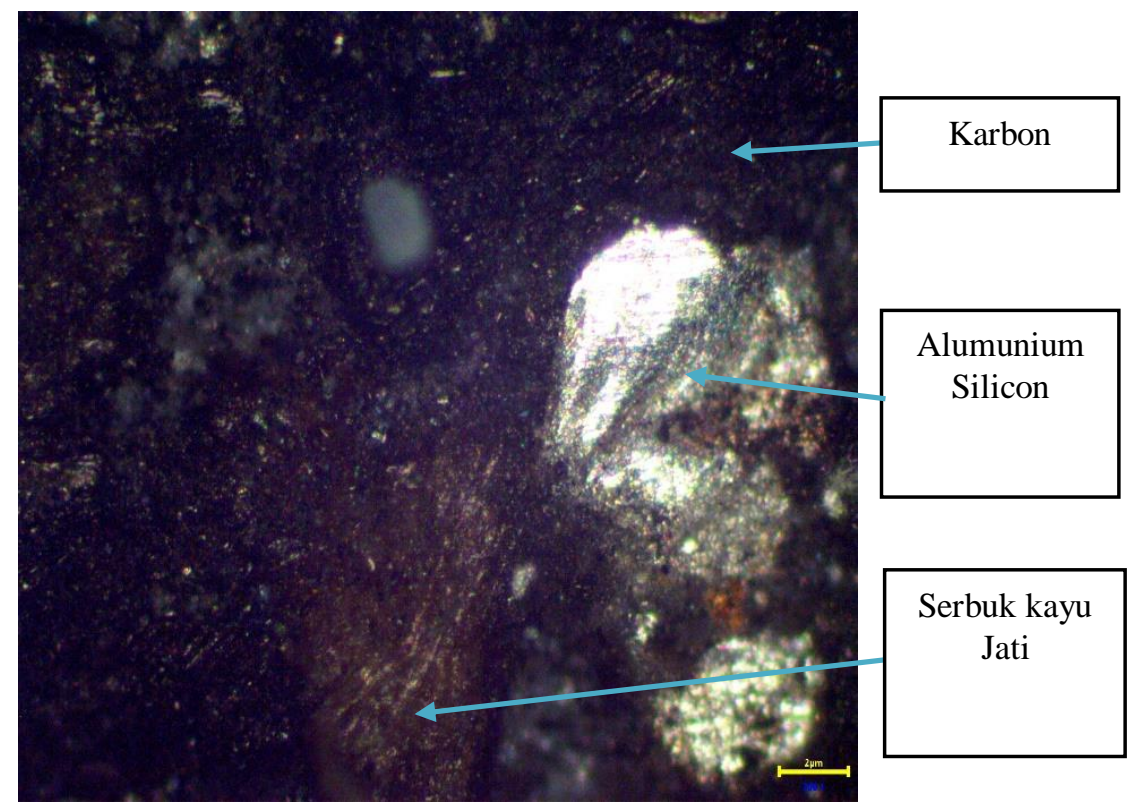

Gambar 1. Foto macro kampas rem mesh 50 sebelum digesek. 
3.1.2. Foto Macro Kampas Rem Mesh 60 Sebelum Digesek

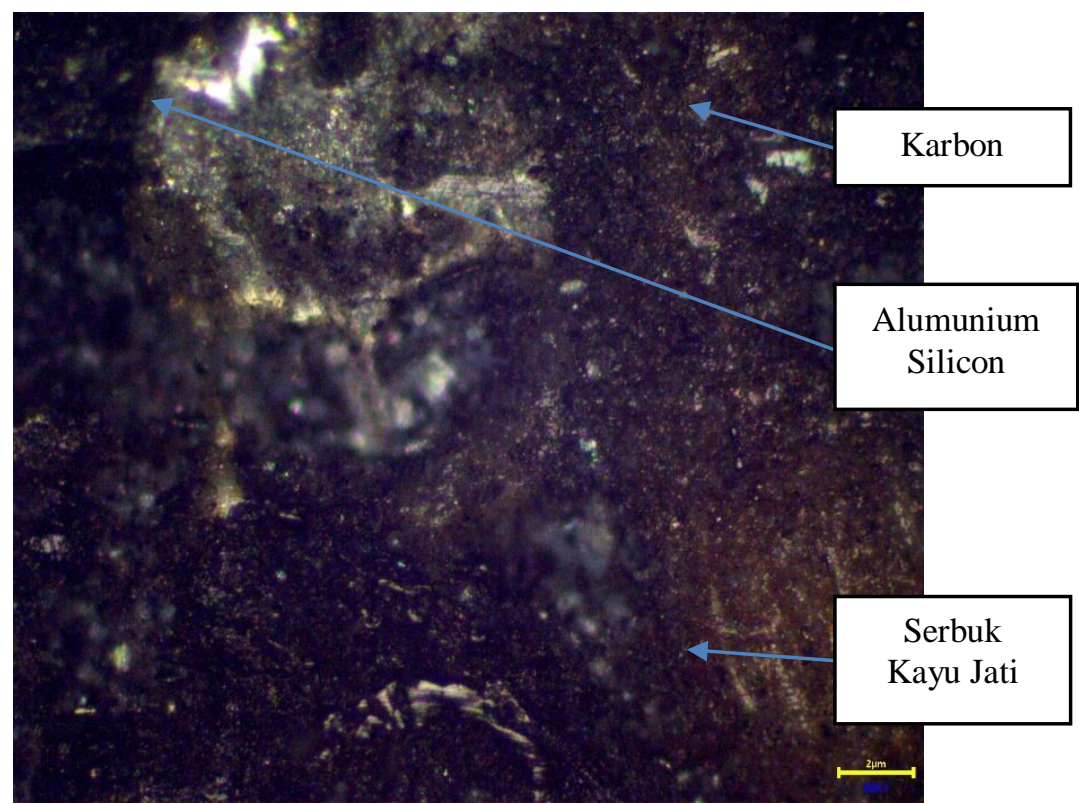

Gambar 2. Foto macro kampas rem mesh 60 sebelum digesek.

Dari foto macro di atas dapat diketahui bahwa untuk kampas rem variasi Mesh 60 mempunyai ikatan partikel yang baik, sedangkan untuk permukaan kampas lebih halus dibandingkan permukaan kampas Mesh 50 dan dapat diketahui ukuran alumunium silicon senilai $60 \mathrm{Mesh}$ atau mendekati $250 \mu \mathrm{m}$.

\subsubsection{Foto Macro Kampas Rem Mesh 100 Sebelum Digesek}

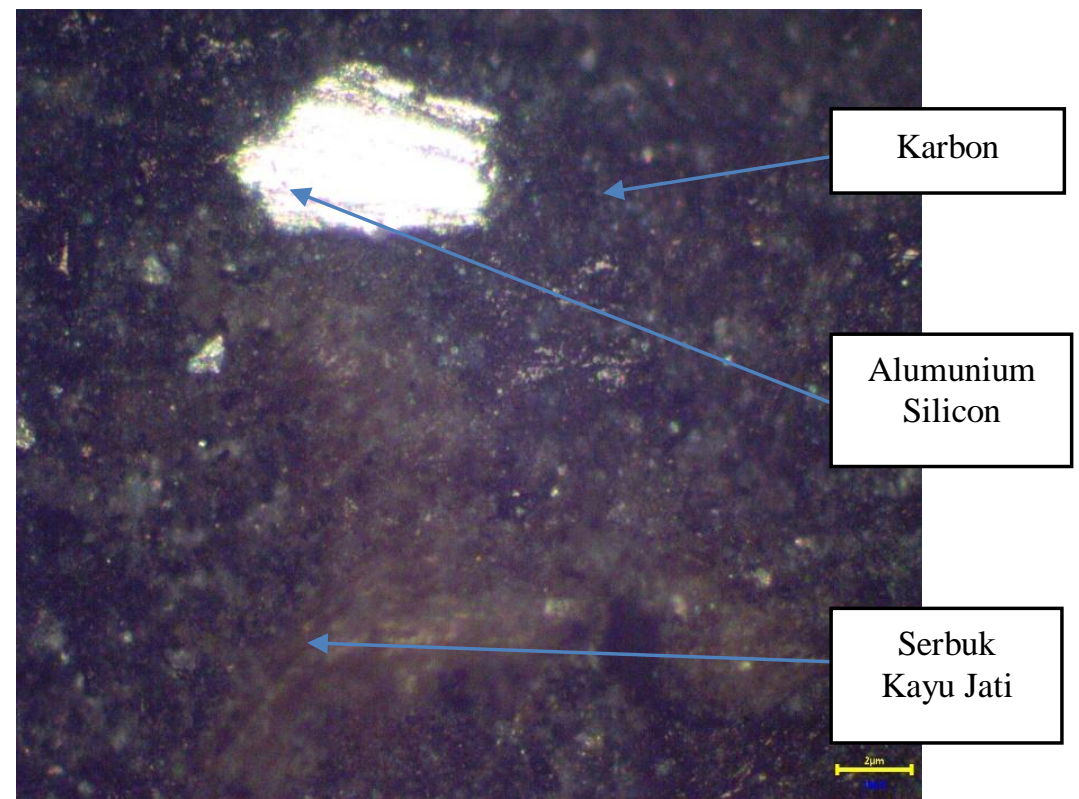

Gambar 3. Foto Macro Kampas Rem Mesh 100 sebelum digesek.

Dari foto macro di atas dapoat diketahui bahwa untuk kampas rem variasi Mesh 100 mempunyai ikatan partikel yang baik, sedangkan untuk permukaan kampas lebih halus dibandingkan permukaan kampas Mesh 50 dan 60 serta dapat diketahui ukuran alumunium silicon senilai 100 Mesh atau mendekati $150 \mu \mathrm{m}$. 
3.1.4. Foto Macro Kampas Rem Pasaran

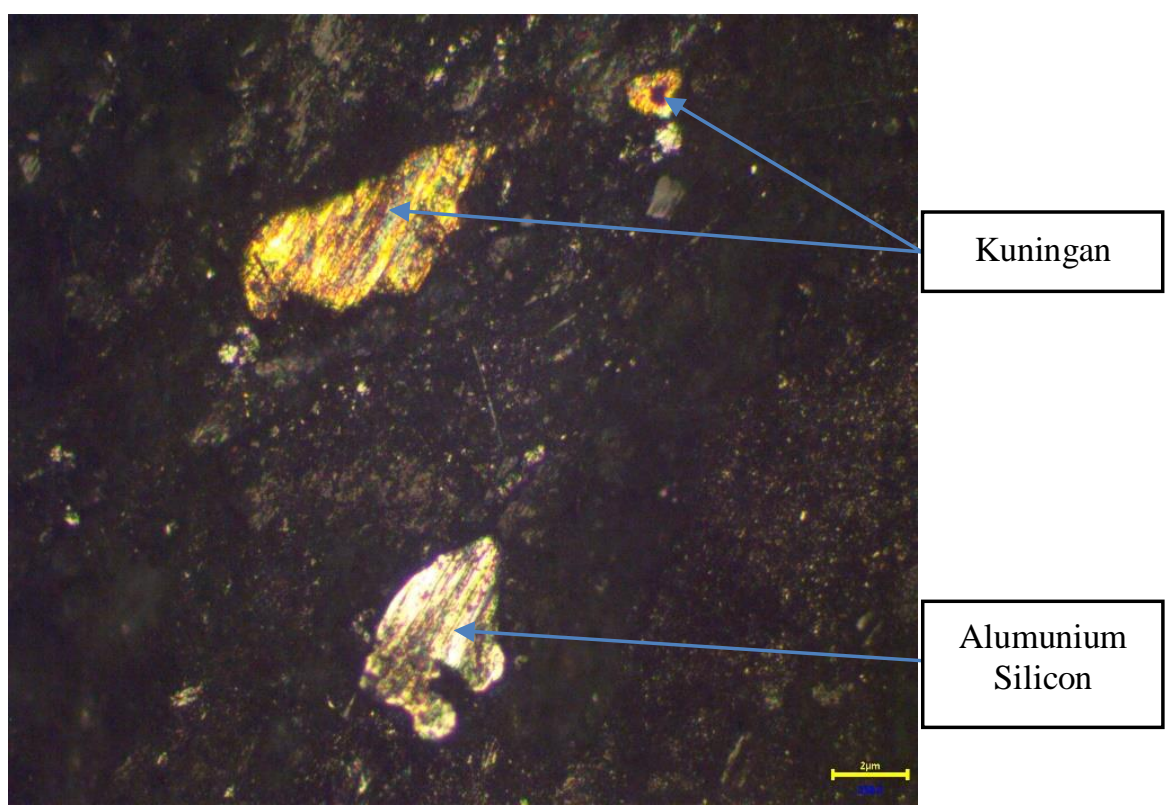

Gambar 4. Foto macro kampas rem pasaran.

Dari foto macro di atas dapat diketahui bahwa untuk kampas rem pasaran mempunyai ikatan partikel yang baik, sedangkan untuk permukaan kampas lebih halus dibandingkan permukaan kampas Mesh 50, 60, dan 100, serta dapat diketahui ukuran Alumunium Silicon senilai 100 Mesh atau mendekati $150 \mu \mathrm{m}$.

\subsection{Hasil pengujian kekerasan Durometer Shore D.}

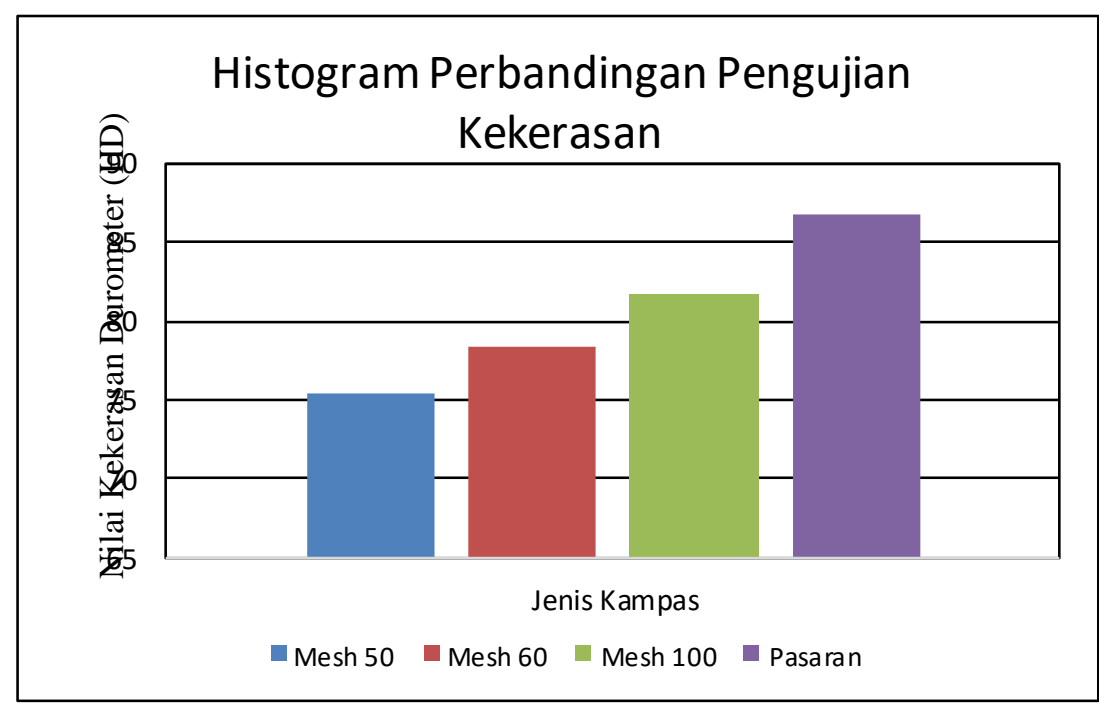

Gambar 5. Grafik perbedaan nilai kekerasan kampas rem setelah di oven.

Hasil pengujian kekerasan didapatkan nilai tertinggi pada kampas Pasaran sedangkan yang mendekati yaitu variasi Mesh 100, sehingga dapat disimpulkan semakin padat butiran maka kampas semakin keras, sementara penambahan serbuk kayu jati dapat menurunkan kekerasan dikarenakan sifat fisik serbuk yang lebih lunak. 


\subsection{Hasil pengujian keausan rata-rata}

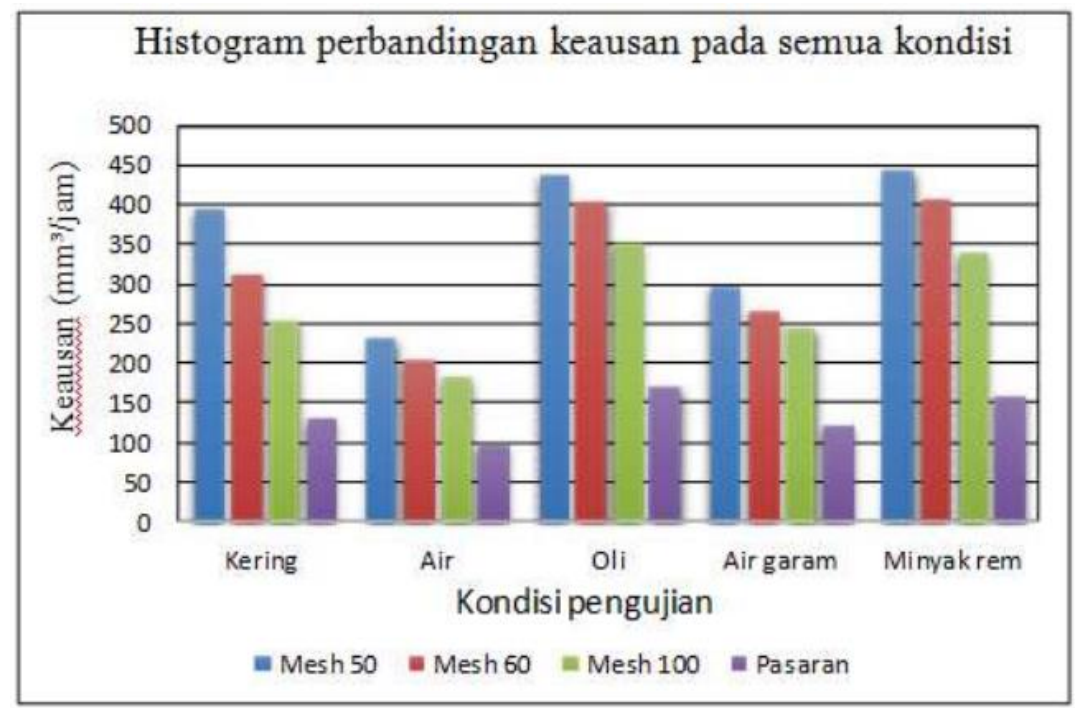

Gambar 6. Grafik hubungan antara jenis kampas rem dengan pengaruh kondisi pengujian terhadap keausan ratarata

Hasil data didapatkan nilai keausan kampas Pasaran lebih sedikit dibandingkan dengan kampas serbuk kayu jati dengan variasi Mesh 50, 60, dan 100, dikarenakan struktur kampas Pasaran mempunyai struktur yang keras dan padat.

\subsection{Hasil perhitungan daya rata-rata}

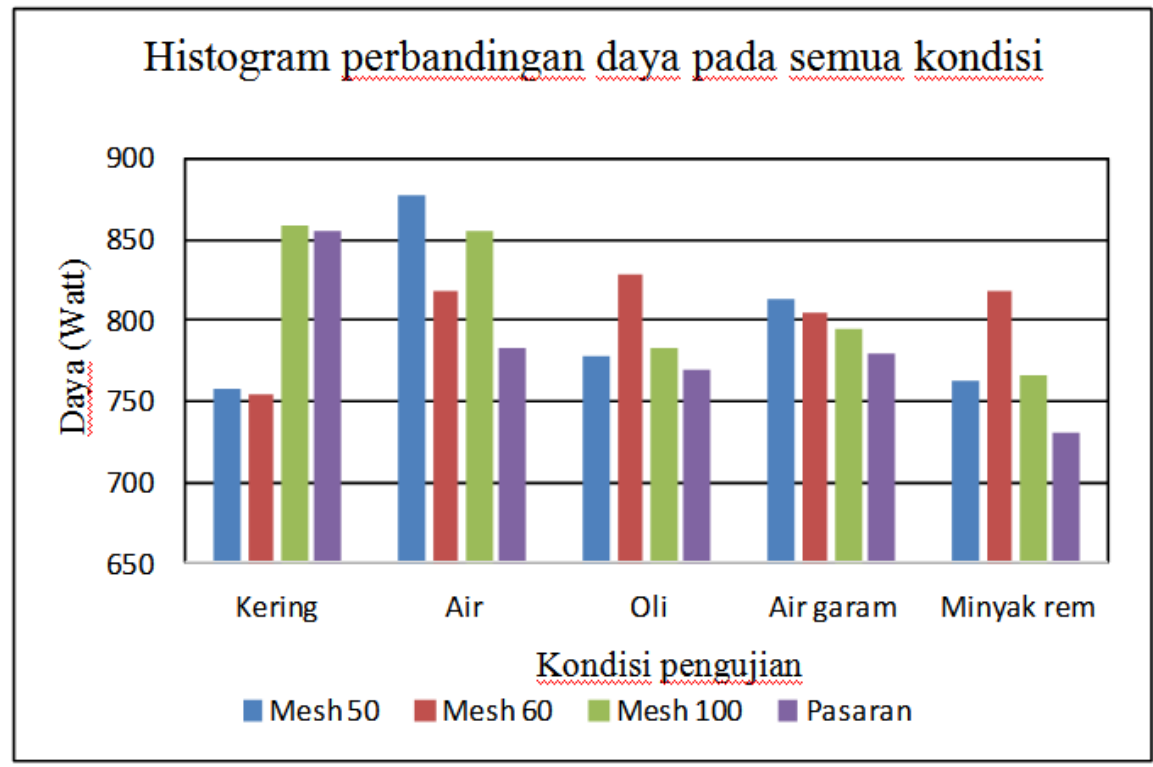

Gambar 7. Grafik hubungan antara jenis kampas rem dengan pengaruh kondisi pengujian terhadap daya rata-rata

Hasil data pada kampas rem kondisi kering yang memiliki daya tertinggi yaitu variasi Mesh 100, kondisi air dan air garam tertinggi pada variasi Mesh 50, sedangkan pada kondisi oli dan minyak rem tertinggi pada variasi Mesh 60. Hasil ini akan berpengaruh terhadap nilai dari besar kecilnya Torsi. 


\subsection{Hasil Perhitungan Kecepatan Sudut Rata-Rata.}

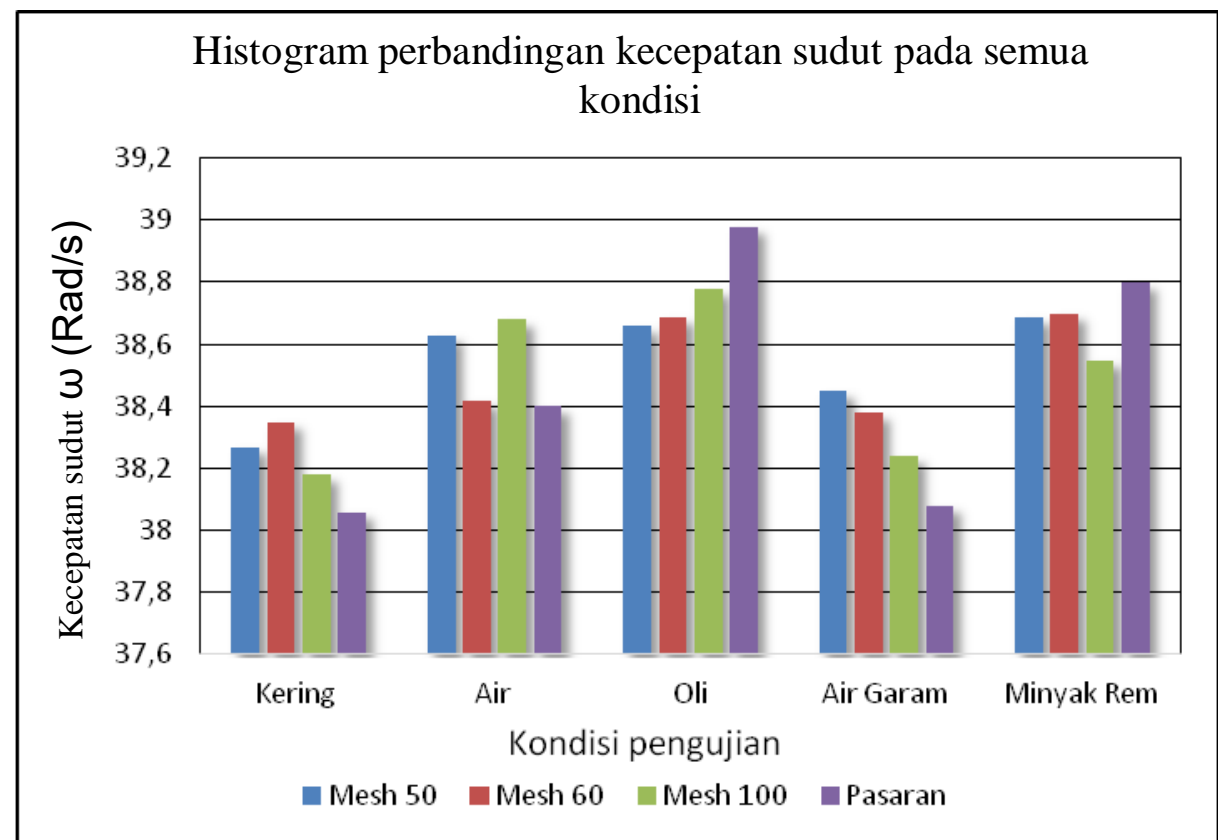

Gambar 8. Grafik hubungan antara jenis kampas rem dengan pengaruh kondisi pengujian terhadap kecepatan sudut rata-rata

Hasil data di atas didapatkan nilai kecepatan sudut yang saling mendekati nilainya, maka jika dirata-rata secara berurutan, nilai tertinggi dari pengujian adalah kondisi oli, air garam, air, minyak rem, kemudian kering. hal ini berpengaruh pada hasil Torsi, bila kecepatan sudut semakin kecil maka Torsi yang didapatkan semakin besar.

\subsection{Hasil Perhitungan Torsi Rata-Rata.}

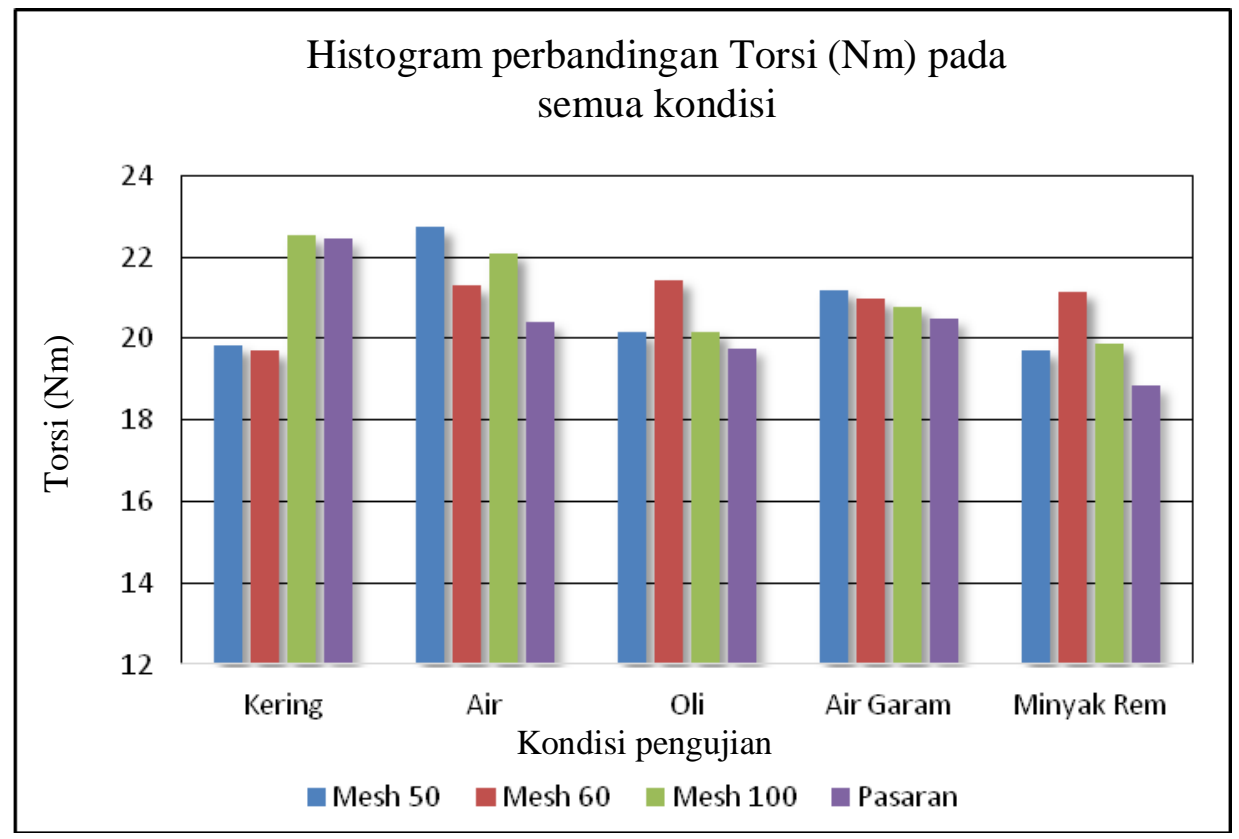

Gambar 9. Grafik hubungan antara jenis kampas rem dengan pengaruh kondisi pengujian terhadap torsi (nm) rata-rata

Hasil data di atas nilai Torsi tertinggi pada kondisi kering yaitu variasi Mesh 100, pada kondisi air dan air garam tertinggi pada variasi Mesh 50, sedangkan pada kondisi oli dan minyak rem tertingggi pada variasi Mesh 60. Hal ini berpengaruh pada Koefisien Gesek, bila semakin besar Torsi maka Koefisien Gesek akan semakin besar. 


\subsection{Hasil Perhitungan Koefisien Gesek.}

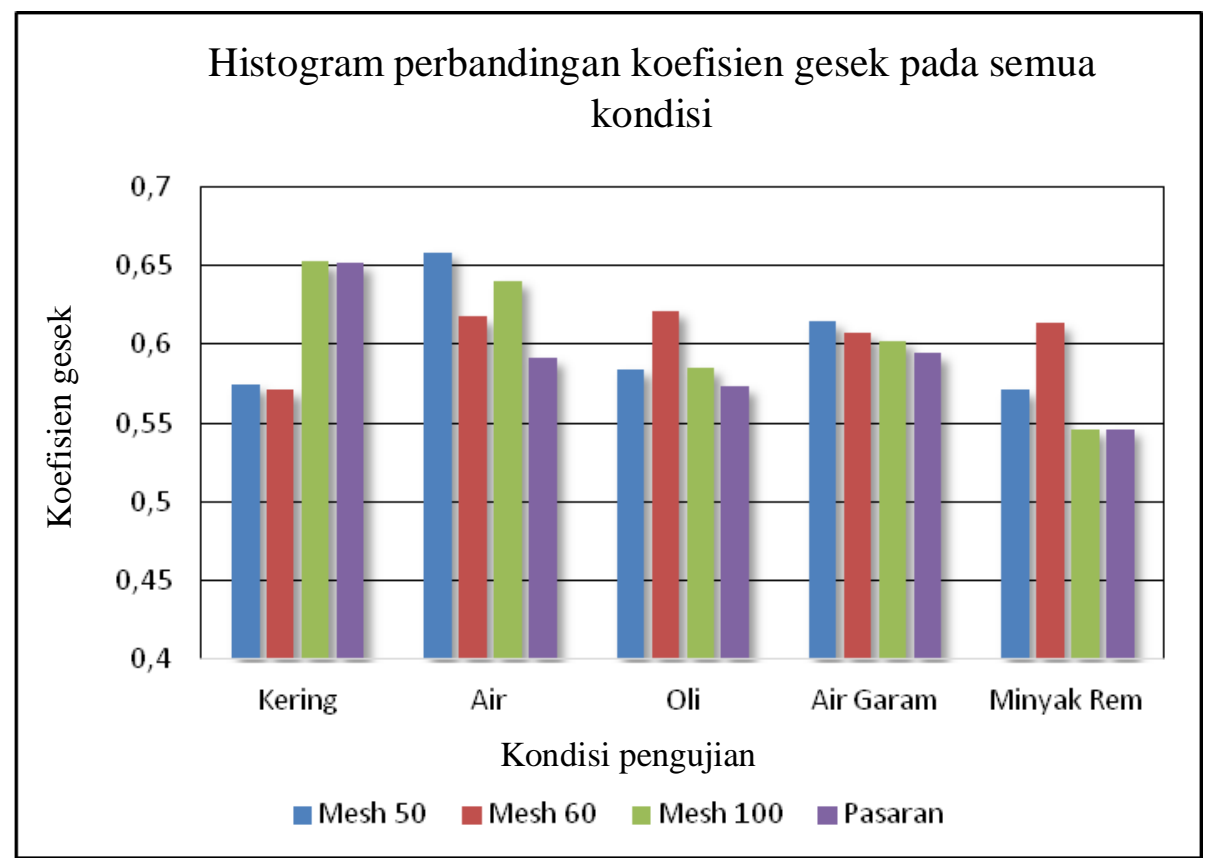

Gambar 10. Grafik hubungan antara jenis kampas rem dengan pengaruh kondisi pengujian terhadap koefisien gesek rata-rata

Hasil data di atas didapatkan nilai Koefisien Gesek tertinggi pada kondisi kering ada 2 yaitu pada variasi Mesh 100 dan kampas rem pasaran, pada kondisi air dan air garam variasi Mesh 50 adalah yang tertinggi, sedangkan pada kondisi oli dan minyak rem tertinggi pada variasi Mesh 60, hal ini berpengaruh dengan hasil pengereman, apabila semakin besar nilai Koefisien Gesek maka pengereman akan lebih cepat.

\subsection{Hasil pengamatan suhu akhir}

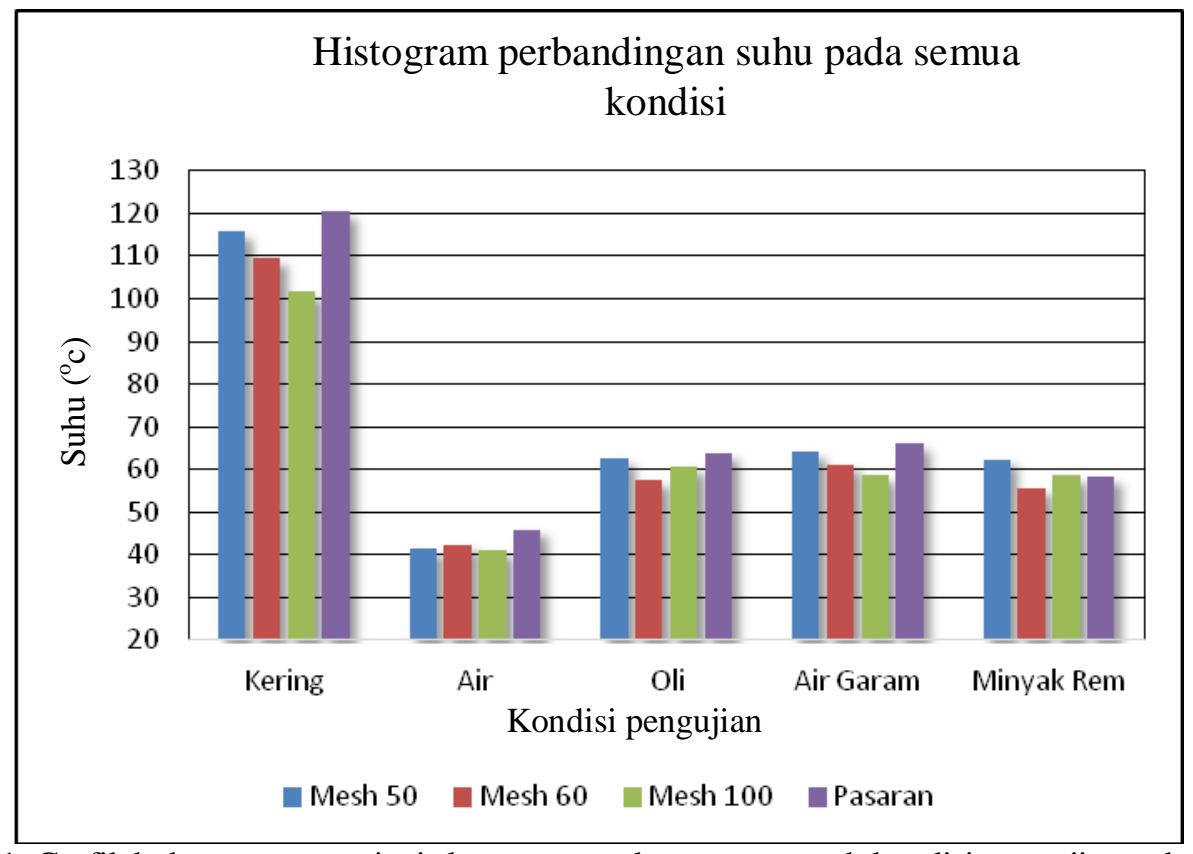

Gambar 11. Grafik hubungan antara jenis kampas rem dengan pengaruh kondisi pengujian terhadap suhu ratarata.

Hasil di atas menunjukkan bahwa kampas Pasaran rata-rata memiliki suhu yang lebih tinggi dibandingkan dengan kampas serbuk kayu jati dengan variasi Mesh 50, 60,100, maka suhu kampas serbuk kayu jati akan lebih 
dingin dikarenakan sifat dari serat yang mudah menyerap panas dan menyebarkanya ke seluruh wilayah bahan gesekan, sehingga mudah melepaskan panas lebih cepat, dan menghambat terjadinya suhu yang berlebihan.

\subsection{Hasil pengujian foto macro kampas rem sesudah digesek}

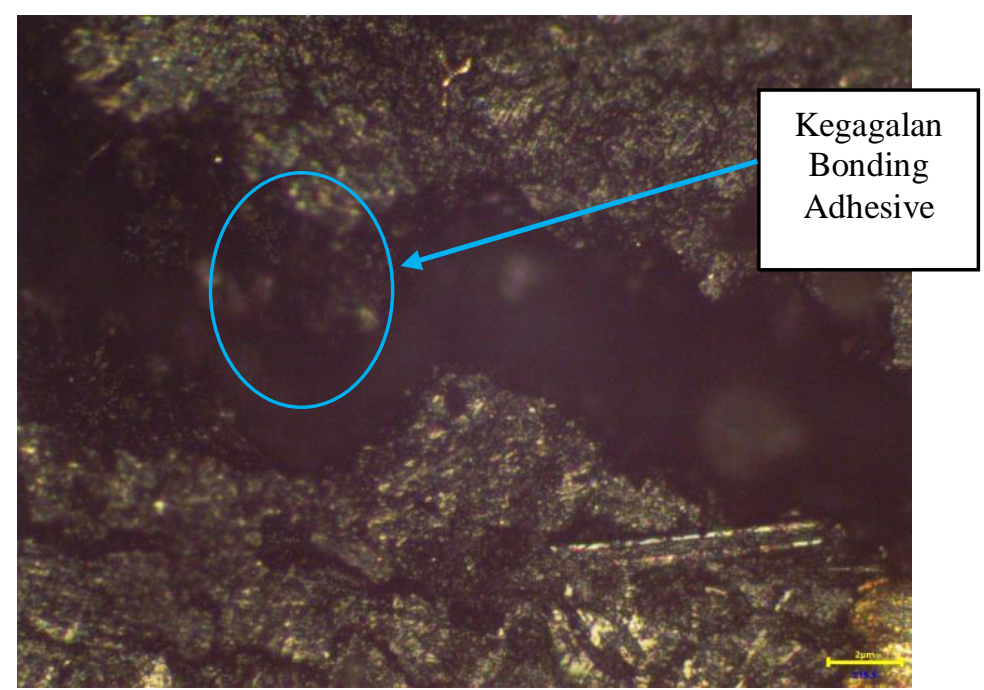

Gambar 12. Foto kampas rem mesh 50 sesudah digesek.

Dari foto macro di atas dapat diketahui bahwa untuk kampas rem variasi Mesh 50 mengalami kegagalan Bonding Adhesive, yang terjadi karena kurangnya ikatan antara partikel dan serbuk yang mengakibatkan terlepasnya serbuk dari perekatnya atau Phenolic Resin.

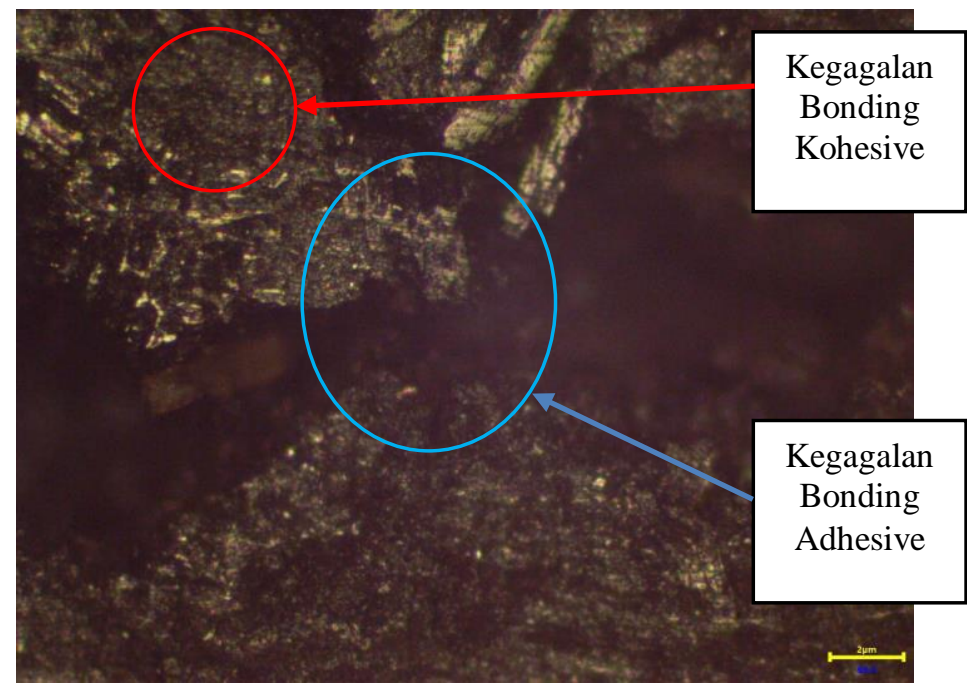

Gambar 13. Foto kampas rem mesh 60 sesudah digesek.

Dari foto macro di atas dapat diketahui bahwa untuk kampas rem variasi Mesh 60 mengalami kegagalan Bonding Adhesive dan kegagalan Bonding Kohesive, yang terjadi karena kurangnya ikatan antara partikel dan serbuk yang mengakibatkan terlepasnya serbuk dari perekatnya atau Phenolic Resin dan terjadi perpatahan yang terjadi pada lapisan perekat. 


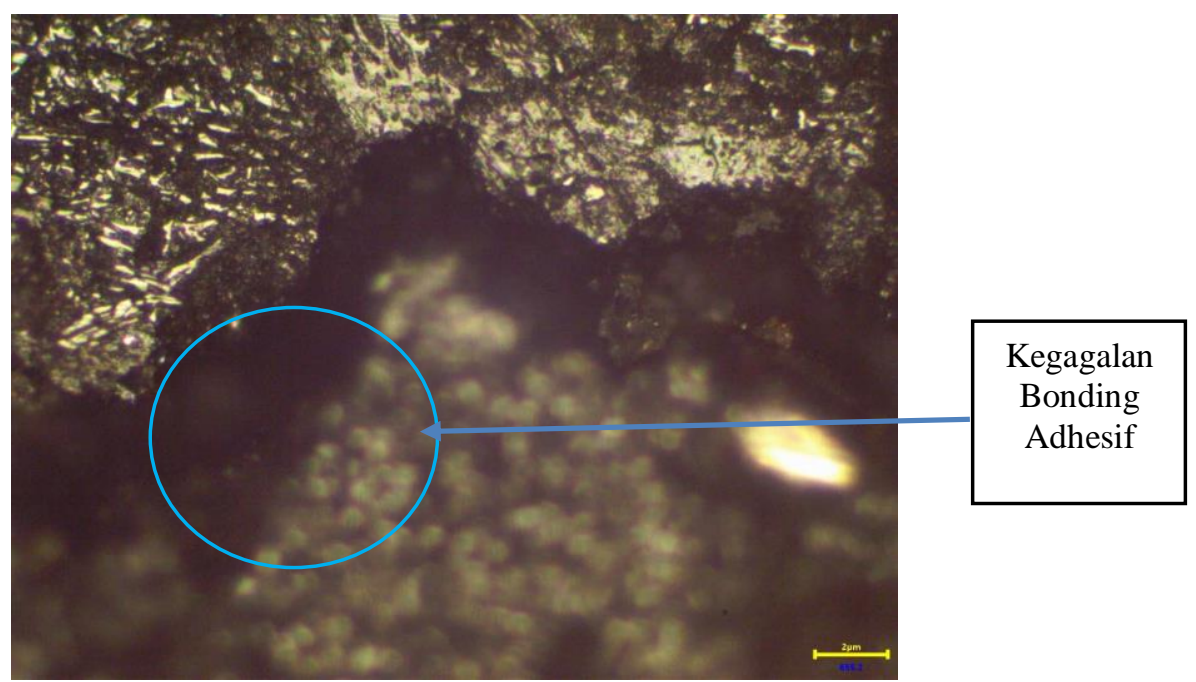

Gambar 14. Foto kampas rem mesh 100 sesudah digesek.

Dari foto macro di atas dapat diketahui bahwa untuk kampas rem variasi Mesh 100 mengalami kegagalan Bonding Adhesive, yang terjadi karena kurangnya ikatan antara partikel dan serbuk yang mengakibatkan terlepasnya serbuk dari perekatnya atau Phenolic Resin.

\section{PENUTUP \\ Kesimpulan}

Nilai kekerasan kampas rem pasaran lebih besar yaitu 86,75 Skala Shore D, sedangkan kekerasan yang mendekati yaitu kampas serbuk kayu jati dengan variasi Mesh 100 yaitu 81,60 Skala Shore D dan terendah pada variasi Mesh 50 yaitu 75,45 Skala Shore D, maka dapat disimpulkan bahwa semakin kecil butir Mesh Alumunium Silicon dapat mempengaruhi peningkatan nilai kekerasan pada kampas rem berbahan dasar alami serbuk kayu jati. Selain itu pencampuran bahan dan tekanan pada saat Kompaksi bisa mempengaruhi perbedaan nilai kekerasan kampas rem.

Hasil pengujian keausan menunjukkan kampas rem Pasaran lebih kecil tingkat keausanya dikarenakan struktur yang keras dan padat. Sedangkan yang mendekati yaitu kampas rem serbuk kayu jati dengan variasi Mesh 100 pada pengaruh kondisi air dengan nilai 182,29 $\mathrm{mm}^{3} / \mathrm{jam}$. Dan keausan tertinggi pada Alumunium Silicon Mesh 50 pada pengaruh minyak rem dengan nilai 443,75 $\mathrm{mm}^{3} / \mathrm{jam}$. Maka dapat disimpulkan bahwa semakin kecil butir Mesh Alumunium Silicon (Al-Si) dapat memperlambat nilai keausan kampas rem.

Berdasarkan hasil pengujian gesek menunjukkan bahwa nilai koefisien gesek tertinggi pada kondisi kering yaitu pada variasi Mesh 100 yaitu 0,652 dan mendekati dengan kampas rem Pasaran yaitu 0,651. Pada kondisi air dan air garam yang tertinggi pada variasi Mesh 50 yaitu kondisi air 0,658 dan kondisi air garam 0,614. Sedangkan pada kondisi oli dan minyak rem yang tertinggi pada variasi Mesh 60 yaitu kondisi oli 0,621 dan kondisi minyak rem 0,613. Maka dapat disimpulkan bahwa smakin kecil butir Mesh Alumunium Silicon akan meningkatkan nilai koefisien gesek. Hasil ini diperoleh dari perhitungan Torsi dengan kesimpulan semakin besar Torsi maka koefisien gesek akan semakin besar yang akan mempengaruhi pada saat proses pengereman kampas rem.

\section{Saran}

Hasil dari penelitian ini, penulis mempunyai beberapa saran untuk dilakukan pada penelitian selanjutnya dalam proses pengembangan dalam pembuatan kampas rem yaitu:

a. Pada proses pembuatan bahan Alumunium Silicon (Al-Si) agar dapat menggunakan butir Mesh terkecil.

b. Proses pembuatan kampas rem diusahakan menggunakan penekanan beban yang lebih tinggi, agar memperoleh struktur kampas yang lebih padat.

c. Proses Kompaksi dan Sintering dilakukan dengan cepat, sehingga pemanas perlu menggunakan Heater yang berdaya lebih tinggi.

d. Proses pengujian, sebaiknya menggunakan alat uji yang kelayakannya berstandar agar dapat mendapatkan data yang optimal dan akurat. 


\section{DAFTAR PUSTAKA}

Badan Standardisasi Nasional. (1992). Cara Uji Ketahanan Terhadap Air, Larutan Garam, Minyak Pelumas dan Cairan Rem Untuk Kampas Rem Kendaraan Bermotor (SNI 09-2663-1992). Badan Standardisasi Nasional: Jakarta.

Baharuddin. (2005). Pemanfaatan Serbuk Kayu Jati (Tectona Grandis L.) Yang Direndam Dalam Air Dingin Sebagai Media Tumbuh Jamur Tiram (Pleurotus Comunicipae). Laporan Tugas Akhir Jurusan Kehutanan, Universitas Hasanuddin, Kampus Tamalanrea, Jl. Perintis Kemerdekaan Km. 10, Makasar.

Gibson, Ronald F. (1994). Principles Of Composite Material Mecanic. McGraw-Hill International book company: New york.

Hashemi, Javad dan William F, Smith. (2005). Foundation Of Materials science And Engineering. McGraw-Hill International book company: New york.

Irfan, Pramuko I.P, Ngafwan. (2009). Pengaruh Variasdi Tekanan Kompaksi Terhadap Ketahanan Kampas Rem Gesek Sepatu. Laporan Tugas Akhir Fakultas Teknik Mesin, Universitas Muhammadiyah Surakarta, Agustus 2009, Surakarta.

Khoirul. (2017). Pengaruh Ukuran Besar Butir Tembaga $(\mathrm{Cu})$ Terhadap Nilai Kekerasan, Keausan, dan Koefisien Gesek Kampas Rem. Laporan Tugas Akhir Jurusan Teknik Mesin, Universitas Muhammadiyah Surakarta.

Kiswiranti, Desi. (2007). Pemanfaatan Serbuk Tempurung Kelapa Sebagai Alternatif Serat Penguat Bahan Friksi Non-Asbes Pada Pembuatan Kampas Rem Sepeda Motor. Laporan Tugas Akhir Jurusan Fisika, Fakultas Matematika Dan Ilmu Pengetahuan Alam, Universitas Negeri Semarang, Semarang.

Pramuko, I.P, Diki Awaludin. (2018). Variasi Ukuran Mesh pada (Al-Si) dan Karbon Tempurung Kelapa Dengan Menggunakan Polyester BQTN 157 Terhadap Nilai Pengujian Kekerasan, Keausan dan Koefisien Gesek Kampas Rem. Laporan Tugas Akhir Jurusan Teknik Mesin, Universitas Muhammadiyah Surakarta.

Smith, William F. (1990). Principles of Material Science and Engineering, second edition. Mc. Graw Hill Publishing Company: New York.

Utomo, Joko. (2017). Pengaruh Variasi Serbuk Getah Kulit Mete (cnsl) Dengan Matrik Phenolic Resin Terhadap Tingkat Kekerasan, Keausan, dan Koefisien Gesek Sebagai Bahan Alternatif Kampas Rem Non-Asbestos. Laporan Tugas Akhir Jurusan Teknik Mesin, Universitas Muhammadiyah Surakarta. 